\title{
Caracterización de una pedagogía de la teología en perspectiva crítico-liberadora. Reflexiones desde la pedagogía crítica y la teología de la liberación"
}

\author{
Juan Esteban Santamaría Rodríguez ${ }^{* *}$ \\ Eduard Andrés Quitián Álvarez*** \\ Alba Luz Orozco Bernal ${ }^{* * * *}$
}

Recibido: 2 de marzo de 2016. • Aprobado: 1 de mayo de 2016.

* El presente artículo es resultado del proyecto de investigación denominado: "Presupuestos epistemológicos para la fundamentación de una pedagogía de la teología”. Este proyecto fue financiado por el Centro de Investigación de la Vicerrectoría de Universidad Abierta y a Distancia (VUAD) de la Universidad Santo Tomás en el marco de la convocatoria interna 10 de 2015.

* Magíster en Teología y Licenciado en Teología de la Pontificia Universidad Javeriana. Trabaja actualmente en la Facultad de Educación de la Universidad Santo Tomás en el programa de Licenciatura en Teología. Ejerce el cargo de profesor con funciones de docencia, investigación, proyección social y gestión académico-administrativa. Correo electrónico: juanesantamaria@ ustadistancia.edu.co

*** Magíster en Filosofía y Filósofo de la Universidad de los Andes. Licenciado en Ciencias Religiosas de la Universidad de La Salle. Trabaja actualmente en la Facultad de Educación de la Universidad Santo Tomás. Ejerce el cargo de Director de Programa de Licenciatura en Filosofía y Educación Religiosa y Licenciatura en Teología. Correo electrónico: eduardquitian@ustadistancia. edu.co

**** Estudiante del programa de Licenciatura en Teología de la Universidad Santo Tomás. Licenciada en Ciencias Religiosas de la Pontificia Universidad Urbaniana (Roma). Actualmente es Asistente de Investigación del proyecto 'Contenidos curriculares para la fundamentación de una pedagogía de la teología' y docente en el Colegio Minuto de Dios. Siglo XXI. Correo electrónico: albaorozco@ustadistancia.edu.co 


\title{
Resumen
}

El artículo propone una pedagogía de la teología en perspectiva crítico-liberadora. Para ello, recurre a los fundamentos de la pedagogía crítica y la teología de la liberación, referentes que indagan por las características del acto educativo y el significado de la experiencia de fe cristiana desde la realidad histórica del sujeto respectivamente. La interacción dialógica entre ambos saberes fundamenta esta pedagogía al reconocer el rol del creyente (profesor - estudiante) como 'intelectual transformativo', quien a través de la significación de su experiencia de fe en su contexto; su inteligibilidad en relación con la tradición teológica eclesial y el despliegue de una praxis liberadora que contribuya a la transformación de realidades de opresión en contextos de liberación y salvación posibilita la construcción y enseñanza del saber teológico.

Palabras clave: Pedagogía de la teología, pedagogía crítica, teología de la liberación, enseñabilidad, saber teológico

\section{Characterization of a teaching of theology in critical- liberation perspective. Reflections from the critical pedagogy and liberation theology}

\begin{abstract}
The article proposes a pedagogy of theology in critical-liberating perspective. To do this, it uses the fundamentals of critical pedagogy and theology of liberation, referring to investigate the characteristics of the educational act and the meaning of the experience of christian faith from the historical reality of the subject respectively. Dialogic interaction between knowledge bases this pedagogy recognizing the role of the believer (teacher-student) as 'intellectual transformative', who through the significance of their faith experience in context; intelligibility regarding the Church's theological tradition and deployment of a liberating praxis that contributes to the transformation of realities of oppression in the context of liberation and salvation make possible the construction and teaching of theological knowledge.
\end{abstract}

Keywords: Pedagogy of theology, critical pedagogy, theology of liberation, theacheability, theological knwoledge. 


\section{Caractérisation d'une pédagogie de la théologie dans une perspective critique-libératrice. Réflexions depuis la pédagogie critique et la théologie de la libération}

\section{Résumé}

L'article propose une pédagogie de la théologie dans une perspective critique-libératrice. Pour cela, il a recourt aux fondements de la pédagogie critique et de la théologie de la libération, référents qui enquêtent à travers les caractéristiques de l'acte éducatif et du sens de l'expérience de la foi chrétienne depuis la réalité historique du sujet respectivement. L'interaction dialogique entre les deux savoirs établit cette pédagogie en reconnaissant le rôle du croyant (professeur-étudiant) comme « intellectuel transformateur », qui à travers de la signification de son expérience de foi dans son contexte, son intelligibilité en relation avec la tradition théologique ecclésiale et le déploiement d'une pratique libératrice qui contribue à la transformation de réalités d'oppression dans des contextes de libération et de salut, facilite la construction et l'enseignement du savoir théologique.

Mots-clés: Pédagogie de la théologie, pédagogie critique, théologie de la libération, enseignement, savoir théologique.

\section{Introducción}

Caracterizar una pedagogía de la teología implica realizar un ejercicio de interacción dialógica entre dos saberes específicos: pedagogía y teología. Desde el campo de la pedagogía son muchas las perspectivas a partir de las cuales es posible realizar un proceso de enseñabilidad de los saberes. Así mismo, desde el horizonte de la teología católica, también es pertinente señalar que al interior de la Iglesia existen mediaciones y modelos propios para desarrollar y transmitir el contenido de la fe. Prueba de ello son los documentos del Concilio Vaticano II, el Catecismo de la Iglesia Católica (CEC 4 - 10), la Exhortación Apostólica Catechesi Tradendae (CT), y los métodos adoptados por la teología a fin de desarrollar, comunicar y transmitir el significado de la fe, su razonabilidad e implicaciones para los creyentes al interior de la Iglesia (Wicks, 2011).

En sintonía con lo anterior, el interés de esta reflexión es aportar al desarrollo de la enseñabilidad del saber teológico. Para ello, toma como referentes la pedagogía crítica y la teología de la liberación, saberes que en el contexto 
latinoamericano surgen como resultado de la apropiación de los procesos de liberación, emancipación y transformación que los pueblos marginados del continente emprenden frente a su realidad de opresión. La pedagogía crítica realiza este ejercicio y señala la importancia del desarrollo del pensamiento crítico del sujeto como resultado de sus experiencias vitales. La teología de la liberación lo hace al tener en cuenta el dinamismo que adquiere la experiencia de fe cristiana desde los anhelos, luchas, esperanzas y acciones de liberación y transformación de la realidad que realizan las mayorías empobrecidas.

Así las cosas, la interacción entre estos dos saberes aporta al desarrollo de dicha pedagogía en dos perspectivas. En primera instancia, concibiendo el acto educativo como un proceso para la emancipación intelectual de los sujetos frente a su realidad; y en un segundo momento, señala la importancia de la experiencia de fe como mediación fundamental para dar razón del saber teológico. Al respecto, es necesario precisar que el conocimiento teológico está mediado por la experiencia de fe (Berríos, 2012: p. 188), su inteligibilidad y el despliegue de una praxis como estrategia para la transformación de la realidad. De ahí la pertinencia de esta reflexión en torno al proceso pedagógico, ya que su articulación e implicaciones histórico-sociales dependen de esta razonabilidad de la fe (Gutiérrez, 1990: p. 58) en el marco de la realidad histórica del creyente.

\section{Aportes para una pedagogía de la teología: reflexiones desde la pedagogía crítica y la teología de la liberación.}

\subsection{Pedagogía crítica}

El elemento fundante de la pedagogía crítica es la cultura. En ella y desde ella son cultivados los valores y acciones que los sujetos emprenden en relación directa con su realidad. Al respecto, es importante señalar que la noción de cultura que concibe esta reflexión pedagógica se caracteriza por establecer serias diferencias con su significado tradicional. De esta manera, la cultura más que un espacio de normalización social es concebida como un escenario de disociación, de ruptura y de constante transformación de acuerdo a los intereses de sexo, raza y clase de los sujetos que interactúan en ella (McLaren, 1994: p. 39). Según McLaren, 
La tradición de la pedagogía crítica parte de una concepción particular de la cultura, que está muy alejada de la imagen que regularmente se tiene de ella como espacio monádico de armonía y control. Dentro de la perspectiva crítica, la cultura es un espacio de disociación, de ruptura y de contradicción: un ámbito de protesta contra las estructuras y los poderes prácticos discursivos polivalentes. Es decir, se concibe la cultura como estructura por la combatividad de discursos en disputa. (p. 26)

Esta apreciación permite afirmar cómo la reflexión en torno al acto educativo-crítico tiene una razón histórica y cultural a partir del cual se desarrolla. Así mismo, da a entender cómo la cultura es un escenario de ruptura frente a las relaciones hegemónicas de poder (McLaren, 1984: p. 211), discursivas y prácticas que regularmente los actores políticos y las élites de una sociedad establecen, con lo cual generan marginación y exclusión social de la mayoría poblacional.

Resulta pertinente señalar que la pedagogía crítica, al referirse a este tipo de ruptura que realiza con los patrones hegemónicos de una cultura, da cuenta de la urgencia de una praxis pedagógica liberadora al interior de la escuela que haga efectivo este proceso (McLaren, 1994: p. 47). Uno de los principales intereses para llegar a tal fin es desarrollar el pensamiento crítico y la capacidad de análisis de realidad de los sujetos desde sus experiencias vitales y sociales. Desde esta perspectiva, tanto el docente como el estudiante se presentan como agentes orgánicos del acto educativo, quienes a través de su interacción histórica y cultural, posibilitan la construcción de saberes, y desarrollan reflexiones y acciones encaminadas hacia su emancipación social, para establecer así formas de lucha intelectual y social que deslegitimen la cultura dominante, pues en este patrón de sociedad hegemónica "la enseñanza no refleja la ideología dominante, sino que la constituye" (Giroux, 1997: p. 55).

La relevancia del discurso contra-hegemónico orienta la dinámica de esta pedagogía hacia una praxis y reflexión pedagógica que le otorgue identidad y poder a los sujetos desde sus particularidades históricas (McLaren, 1984: p. 196). Esta pedagogía no hace diferenciación entre grupos socialmente excluidos, antes bien, se interesa por otorgarles un lugar social en la escuela a partir del cual puedan desarrollarse en razón de sus necesidades e intereses. De esta manera, es importante resaltar que la tradición pedagógica-crítica no solo hace una diferenciación al respecto del significado de la cultura, sino también de la escuela, ya que señala su pertinencia como lugar de resistencia así como de emancipación intelectual y social del sujeto. En palabras de Giroux, 
Las escuelas sirven como lugares para colocar a los estudiantes en posiciones subjetivas que no contesten las asunciones, disposiciones y dimensiones de la cultura dominante. Pero el aula también se puede convertir en lugar de resistencia, donde los estudiantes combinen las posibilidades contrarias y transgresoras halladas en la cultura de la calle; es decir, donde las discusiones cargadas de concreción existan como posibilidades, donde la autonegación, la desaparición y la renuncia no se conviertan en referentes primarios para la construcción de las identidades raciales, sexuales y de clase. (Giroux, 1997: p. 67)

Esta apreciación reitera la preocupación de la pedagogía crítica no solo en torno al sujeto, sino también al respecto del lugar de influencia en el cual se desarrolla. Así mismo, permite comprender cómo se fundamenta el acto educativo desde la interacción y participación de los sujetos acorde a sus experiencias, necesidades e intereses en contraposición a las posibilidades 'contrarias y trasgresoras' que ofrece la cultura dominante en cuanto al desarrollo intelectual, de su identidad y cultural de los sujetos. Según esto, la escuela y la cultura dejan de ser lugares 'monádicos de armonía y control', esto es, realidades unitarias y determinadas por ciertos patrones culturales, para darle así relevancia a la praxis pedagógica como ejercicio de resistencia, debate y transformación de acuerdo a las circunstancias histórico-sociales de sus protagonistas.

Ahora bien, para lograr tal fin es necesario garantizar que la praxis pedagógica deslegitime las relaciones asimétricas de poder económico, político, social e intelectual que imperan en los modelos culturales y de escuelas tradicionales actuales; así como también hacer propicio el ambiente de la escuela como escenario que contribuya al desarrollo de los estudiantes sin la necesidad de renunciar a sus intereses y necesidades. En este sentido, la pedagogía crítica puede caracterizarse como una forma de política cultural, pues "se plantea como uno de sus objetivos fundamentales el comprender cómo se pueden problematizar las experiencias y necesidades de los estudiantes socialmente construidas y a veces contradictorias" (Giroux, 1997: p. 60).

La problematización de las necesidades y experiencias de los estudiantes es un aspecto fundamental para dar razón al proceso de transformación social que propone esta pedagogía. Su base social le brinda la posibilidad de apostar por una praxis pedagógica cuya pretensión sea multicultural y emergente (McLaren, 1997: p. 252). De esta forma, la pedagogía crítica deconstruye los valores de la escuela colonial, y da lugar a su significación como espacio para la interacción entre los sujetos que participan en ella; y de igual manera, como escenario para 
el debate y la confrontación en torno a la construcción de los saberes desde la eliminación de la opresión y la desigualdad; promocionando así la libertad y la justicia en la sociedad de acuerdo a los valores y subjetividades que emergen de la relación de los sujetos (McLaren, 1984: p. 222).

En este sentido, al comprenderse la pedagogía crítica como una forma de política cultural (Giroux, 1990: p. 156), se alude que su tarea principal es optar por los grupos sociales empobrecidos y excluidos de nuestro tiempo. Su interés no solo es establecer una praxis resistente frente a los patrones hegemónicos que imperan en el marco social dominante, sino posibilitar a los sujetos históricos con el fin de que sean capaces de apropiar su realidad y emanciparse en ella a fin de transformar sus estructuras dominantes. Con lo anterior, se da cuenta de la variación en el significado de la escuela, pues ante sus formas coloniales y tradicionales, resalta su apreciación como espacio de resistencia y transformación social. De esta manera,

[...] la actual revolución en la teoría social demanda un nuevo conjunto de paradigmas críticos en la teoría educativa que cuenten para la heterogeneidad de los discursos pedagógicos y curriculares y la complejidad de la producción de significado en las culturas posmodernas. De esta forma, la teoría educativa poscolonial puede ser vista como una forma de "teoría viajera" que atraviesa tanto los viejos ámbitos disciplinarios como los nuevos, creando nuevos patrones y relaciones de visión sobre las conexiones entre el poder, el discurso y la práctica pedagógica (McLaren, 1997: p. 223).

La diferenciación en el concepto de cultura, de escuela y de praxis pedagógica que señala la pedagogía crítica permite inferir que sus intereses están puestos en el desarrollo de la subjetividad de las personas, en la construcción de significados y experiencias en razón de su situación histórica y en la transformación de los valores hegemónicos de una sociedad a través de la valoración multicultural de los sujetos y la articulación del conocimiento desde sus experiencias vitales (Giroux, 1997: p. 62). Ahora bien, para lograr sus fines propuestos debe tener como referencia dos aspectos que determinan su impacto en la transformación cultural y social de la realidad: el desarrollo intelectual del sujeto (profesor y estudiante), y con ello, su capacidad para establecer un proceso de concientización frente a la historia, de la cual es su protagonista. 
En términos de Giroux, tanto docentes como estudiantes han de considerarse como "intelectuales transformativos" (Giroux, 2001: pp. 64 - 65) al interior del escenario escolar en el cual se desarrollan. Este aspecto es determinante a fin de considerar el papel protagónico que ambos sujetos asumen en el curso de su historia, y a su vez, las implicaciones que trae con respecto a la deconstrucción de los paradigmas hegemónicos que imperan en la cultura y en la escuela tradicional. Un 'intelectual transformativo' es un sujeto que tiene la posibilidad para transformar su realidad al entender su capacidad para inteligir y apropiar aquello que afecta su normal desarrollo y el de la sociedad como consecuencia de la imposición de valores hegemónicos que generan marginación y exclusión social. Desde esta perspectiva,

La categoría de intelectual transformativo es útil desde varios puntos de vista. [...], expresa una forma de dedicación laboral en la que están íntimamente relacionados el pensamiento y la acción, y, en este sentido, ofrece una contraideología a las pedagogías instrumentales y gestionarias, que separan la concepción de la ejecución y desconocen la especificidad de las experiencias y formas subjetivas que configuran la conducta tanto del profesor como del estudiante (Giroux, 1990: p. 150 - 151).

Esta apreciación ayuda a reconocer que es el sujeto aquel que tiene la posibilidad y la capacidad para transformar su realidad. El docente y el estudiante son agentes de su historia, quienes a través de la significación de sus subjetividades y experiencias, se presentan como actores políticos, sociales e históricos capaces de establecer formas de relación e interacción humana orientadas hacia la construcción social del conocimiento. De igual manera, es una apreciación que deconstruye la razón tecnocrática de la escuela (p. 174), pues faculta al sujeto para que vincule su pensamiento y acción en la apuesta por transformar su dinamismo cultural desde la interacción dialógica que se propone entre sujetos, culturas y saberes.

Dentro del discurso de la pedagogía crítica, uno de los factores que la hace relevante es su crítica a los modelos instrumentales de sociedad que se gestan desde la escuela. Prueba de ello es el tipo de sujeto que ésta ofrece al sistema productivo. Hoy en día resulta ser más importante, e ideológicamente más conveniente, un sujeto pasivo que sea capaz de desarrollar una técnica o un oficio específico antes que una persona capaz de inteligir y pensarse a sí mismo, su historia y su futuro con el compromiso de asumir praxis transformadoras que repercutan en la dignificación de las sociedades y de la cultura. 
El 'intelectual transformativo', en contraposición de lo anterior, es agente de su realidad. Es quien gestiona colectivamente el conocimiento; y así mismo, quien desarrolla su capacidad de interacción social a fin de transformar las estructuras hegemónicas y de poder que imperan en su historia (Giroux, 2001: p. 65). Esta apreciación permite señalar que la tarea de la escuela está en construir el conocimiento, no solo desde la interacción y las subjetividades, sino a través del desarrollo del pensamiento crítico de los sujetos frente a lo que viven y experimentan. De ahí que

[...] los profesores deben confirmar la experiencia del estudiante como parte del encuentro pedagógico, para el cual han de ofrecer contenidos curriculares y práctica pedagógicas que encuentren resonancia en las experiencias vitales de los estudiantes. [Y así mismo] [...], no se limiten a hacer que la experiencia sea relevante para los estudiantes, sino que conviertan esa experiencia en algo problemático y crítico; para ello han de investigar los supuestos ocultos de dicha experiencia. La dirección crítica es necesaria para ayudar a los estudiantes a reconocer las implicaciones políticas y morales de sus propias experiencias (McLaren, 1990: p. 18).

El análisis crítico y problemático de la experiencia de los sujetos es el aspecto que particulariza el proceso de concientización al interior de esta pedagogía. No es posible un ejercicio de apropiación de la realidad si antes no se ha realizado una valoración moral de las vivencias de los sujetos, de sus luchas, preocupaciones e intereses, y así mismo, de su relación directa u opuesta frente al sistema políticocultural en el cual se desarrollan. Esta clave de interpretación es aquella que permite establecer el ingente esfuerzo por hacer del acto educativo crítico un espacio para la construcción social del conocimiento, orientado desde contenidos y apuestas que prevalezcan en el desarrollo de los sujetos con un fin específico: la transformación constante de la sociedad hacia la igualdad y la equidad en todos sus ámbitos. De ahí que Giroux establezca que "el conocimiento, antes de que se haga crítico, ha de tener un significado para los estudiantes. El conocimiento (...) es constantemente filtrado por las experiencias, el lenguaje coloquial crítico y los conocimientos mutuos que los estudiantes traen a las aulas"' (Giroux, 1997: pp. 62).

En este sentido, no debe concebirse el acto educativo como un lugar para la legitimación de las relaciones hegemónicas de poder y dominación propio de las sociedades capitalistas y neoliberales (Giroux, 2013: p. 14); antes bien, debe ser un espacio para la emancipación multicultural basado en un modelo pluralista y de integración social. De ahí que el objetivo del acto educativo crítico sea posibilitar 
una tarea de concientización y apropiación crítica del contexto por parte del sujeto, pues es

[...] en la práctica del desvelamiento de la realidad social, en el proceso concientizador, que la realidad [es] aprehendida no como algo que es, sino como devenir, como algo que está siendo. Pero si está siendo, en el juego de la permanencia y el cambio, y si no es ella el agente de ese juego, es que éste resulta de la práctica de los seres humanos sobre ella (Freire, 1988: p. 85).

Según lo anterior, el direccionamiento de la realidad por parte de los sujetos asume un carácter diferenciador frente a su organización por parte del sistema político-cultural dominante. La transformación de la sociedad depende de la interacción de los sujetos en ella. Así las cosas, es posible señalar que la construcción de conocimiento no será un ejercicio academicista, sino experiencial, en donde los intereses de las personas son base para la articulación del saber, cuya perspectiva será de orden dialógico, y a su vez, contribuyente para su desarrollo humano, intelectual e integral en clave emancipatoria (Giroux, 1997: p. 57). Esta es la apuesta de la pedagogía crítica, ahora bien, depende fundamentalmente del despliegue de una praxis pedagógica que libere el acto educativo de su dominación hegemónica para hacer efectiva la transformación histórica, cultural y social de la realidad desde los intereses de los sujetos.

\subsection{Teología de la liberación}

Según Gustavo Gutiérrez, "la teología es un lenguaje sobre Dios" (Gutiérrez, 1995: p. 13). Es, así mismo, un constante esfuerzo por elaborar una reflexión sistemática en torno a la comprensión del misterio de Dios, revelado y encarnado en la persona de Jesús (Jn 1, 14). Y, en atención al Concilio Vaticano II, es un ejercicio hermenéutico y de apropiación de su presencia en los "signos de los tiempos" (GS, 4) de nuestra historia.

La teología es un 'lenguaje sobre Dios', que atiende a su principalidad en la Sagrada Escritura (DV 24), se constituye como mediación que dinamiza y actualiza el mensaje del Evangelio y su praxis a fin de que la experiencia de fe del creyente y de la Iglesia sean auténticas conforme a los 'signos' y realidades históricas que así lo demandan. De ahí que el 'lenguaje' sobre Dios, antes de ser un ejercicio teórico, es una experiencia constitutiva del creyente desde su fe, la cual le permite 
reconocer e interpretar la acción y la presencia de Dios en la historia, y así mismo, apropiar aquello a lo cual le interpela.

En categorías que nos son conocidas, contemplar y practicar es en conjunto lo que llamamos acto primero; hacer teología es acto segundo. Es necesario situarse en un primer momento en el terreno de la mística y de la práctica, sólo posteriormente puede haber un discurso auténtico y respetuoso acerca de Dios. Hacer teología sin la mediación de la contemplación y de la práctica sería estar fuera de las exigencias del Dios de la Biblia (Gutiérrez, 1995: p. 17).

Al tener en cuenta esta apreciación sobre el significado de la teología, hacer referencia a la teología de la liberación obliga a concebir el 'lenguaje sobre Dios' como una reflexión que emerge fruto de la contemplación del acontecer de Dios y de la praxis de fe que demanda en el creyente desde el contexto latinoamericano. La teología de la liberación surge como resultado de la mística contemplativa de la realidad y el despliegue de una praxis de fe en respuesta a la presencia histórica de Dios en los 'signos' de la pobreza, la injusticia, la opresión, la marginación y la exclusión social a los cuales han sido sometidas las mayorías empobrecidas de América Latina (Oliveros, 1990). Es, al mismo tiempo, un 'lenguaje' que se constituye desde la significación teologal que representan las luchas históricas de liberación de estos pueblos en camino hacia la transformación histórico-social de su realidad como lugar de salvación.

De esta forma, es posible señalar que la teología de la liberación es un 'lenguaje sobre Dios' cuyo interés está fundado en la urgencia de la liberación material, histórica y trascendente de la realidad (Ellacuría, 2000a: p. 555). Es, sin lugar a dudas, un 'lenguaje' sobre el lugar que representan los pobres y oprimidos de nuestra historia como realidad de la presencia y la interpelación histórica de Dios. En este sentido, esta “(...) teología es - tomando el doble significado del término griego logos: razón y palabra - palabra razonada, razonamiento hecho palabra" (Gutiérrez, 1995: p. 17). Palabra razonada sobre Dios desde la realidad histórica que dinamiza la experiencia de fe del creyente y de la Iglesia; y así mismo, razonamiento hecho palabra, proclamación y anuncio de un mensaje de liberación y salvación.

La concepción de teología de la liberación a la luz de los aspectos expuestos permite entender su dinamismo sistemático. El acto primero implica dar razón de la contemplación de la presencia histórica de Dios en los pobres y oprimidos del continente y desde la praxis liberadora que demanda como resultado de 
esta experiencia mística (Gutiérrez, 1995: p. 18); su momento segundo supone reflexionar en torno a esa contemplación de Dios en la historia, la praxis teologal y la espiritualidad que subyace desde la praxis de fe del creyente. La teología de la liberación como un 'lenguaje sobre Dios' no es, según lo anterior, una reflexión estática ni intrascendente, antes bien, al comprender el acontecer histórico de Dios desde la realidad de las víctimas de nuestro tiempo y en las luchas de liberación que realizan como consecuencia de la opresión y marginación a las cuales han sido sometidas, es una teología que demanda una praxis de fe que contribuya a la liberación histórica y trascendente de la realidad en solidaridad y resistencia con ellas. Desde esta perspectiva, la teología de la liberación entiende que:

La liberación tiene, a la vez, un carácter salvífico y un carácter histórico. Cuando el cristiano habla de liberación integral está intentando formular, según las exigencias de las mayorías populares en nuestro tiempo, la versión historizada de la salvación. No piensa que la liberación histórica va por un lado, y por otro, la salvación cristiana, sino que la salvación cristiana tiene mucho que dar a la liberación histórica que a su vez, aunque subordinadamente, la liberación histórica es condición necesaria para la historización de la salvación (Ellacuría, 2000a, pp: $648-649)$.

En los términos que Ellacuría propone, el carácter integral de la liberación está articulado desde la liberación histórico-social que emprenden las mayorías empobrecidas. Este aspecto es para el creyente y la teología misma la representación de la salvación, salvación historizada que se concibe desde la liberación de las realidades de opresión. La precisión que señala Ellacuría está en reconocer que el cristiano es quien habla y proclama la liberación, aspecto que corrobora cómo el sentido de toda teología, y particularmente de la teología de la liberación, está estrechamente relacionado a su experiencia de fe en relación directa con su realidad. Ahora bien, para profundizar esta apreciación, es necesario reconocer que en la liberación de las estructuras de opresión y marginación social es en donde se hace visible la salvación que Jesús anuncia y hace efectiva con los pecadores y excluidos de su tiempo (Mt 9, 10 - 13). Y, así mismo, reiterar que la salvación que proclama a quienes han sido perseguidos a causa de la justicia, de la verdad y de la paz (Mt 5, 1 -12) es dinamismo fundamental que contribuye para la liberación de la realidad de aquellas estructuras que atentan contra la dignidad y la libertad humana.

El carácter histórico, liberador y salvífico de esta teología deja entrever que es una experiencia y praxis de fe que se constituye, no solo desde la contemplación 
de la presencia histórica de Dios en la realidad de los pobres, sino también de la persona de Jesús. Previamente fue enunciado que este 'lenguaje' sobre el misterio de Dios también se realiza desde su apropiación en la encarnación y revelación en Jesús $(J n$ 1, 14). De ahí, que sea necesario señalar cómo esta teología también requiere de la articulación de su dinamismo contemplativo y práxico desde la persona de Jesús y su seguimiento histórico a fin de hacer efectiva la liberación y salvación que proclama.

Este seguimiento tiene un evidente carácter histórico, pues no sólo se realiza en la historia, sino que hace de la historia, integralmente entendida, la materia misma del seguimiento, pero tiene al mismo tiempo un carácter trascendente, por cuanto lo tiene aquel a quien se sigue y lo tiene también el Espíritu por el cual y con el cual se sigue, porque el seguimiento está medido y orientado por lo que debe ser el reino de Dios, tal como lo anunció y puso en marcha Jesús (Ellacuría, 2000b: p. 207).

El seguimiento de Jesús supone tener en cuenta dos aspectos importantes. En primer lugar, solo es posible hacerlo efectivo en la historia. Esto corrobora cómo una auténtica experiencia de fe cristiana depende de la vinculación directa del creyente con las necesidades y clamores de su realidad. En un segundo momento, es un seguimiento que asume un carácter trascendente, esto es, dar cuenta que su dinamismo histórico no solo es acción liberadora de las estructuras de opresión y marginación que aquejan a la realidad histórica de los pueblos latinoamericanos, sino también acción salvadora que hace efectivo el Reino de Dios. Estas dos apreciaciones permiten reconocer cómo el seguimiento histórico de Jesús no solo implica apropiar el carácter histórico de su encarnación como Hijo de Dios (Mt 9, 35; Jn 1, 34), sino también sus acciones y el significado histórico, político y social que representan en relación directa a su acción liberadora a favor de los pobres y marginados de su tiempo (Ellacuría, 2000b: pp. 86 - 87).

Ahora bien, para Ellacuría como para varios de los teólogos latinoamericanos que han contribuido al desarrollo de esta teología (Gutiérrez, Sobrino, Segundo, Boff, Trigo, etc.), este reino no ha de entenderse en la forma política o estructural en que se concibe un reinado terrenal (Jn 18, 36). A diferencia del reino que dice entender la sociedad religiosa y política del tiempo de Jesús, es un Reino que promueve la liberación y la dignidad humana en la historia y desde la historia (Lc 9, 11). Desde las víctimas de las distintas formas de violencia de nuestro tiempo (armada, sexual, familiar, etc.), así como también desde las estructuras de exclusión y marginación social de personas y comunidades por su opción y/o condición (LGTBI, 
desplazados, migrantes, pobres, etc.), es un Reino que opta preferencialmente por ellos (DP 733) desde sus luchas, sueños y esperanzas de liberación.

De lo anterior, es posible afirmar que la teología de la liberación como un 'lenguaje sobre Dios' no solo tiene un acto primero y un acto segundo, sino también un 'acto tercero' que exige del creyente y de la Iglesia una praxis de fe (teologal) a través de la cual sea proclamada la liberación histórica de la realidad y su salvación trascendente (Ellacuría, 2000b: p. 237). Es una praxis que asume el mensaje de Jesús, hecho que exige no solo su seguimiento histórico desde los pobres y marginados de nuestra historia; sino también, la apropiación de su vida y su opción por los pobres y excluidos de su tiempo como punto de partida y de llegada de la praxis de fe (teologal). En este sentido, es una praxis teologal que hace efectivo el Reino de Dios, ya que implica desplegar una constante praxis de liberación y salvación de la realidad histórica en relación directa con las luchas y esperanzas de liberación del pueblo. En este sentido,

[...] el reino de Dios no puede dejar de dar toda importancia al pueblo de Dios. Reino de Dios y pueblo de Dios son dos correlatos inseparables. Reino de Dios, en efecto, no sólo junta la trascendencia de Dios con la inmanencia histórica del reino, sino que reclama, inexorablemente, la existencia de un pueblo, entendido estrictamente como tal, como una unidad popular, en la cual tienen plena cabida los desarrollos individuales y personales, incluso en la relación intransferible con Dios, pero que los hace tanto más ricos cuanto más vinculados al carácter comunitario del pueblo de Dios estén (Ellacuría, 2000b: p. 208).

Liberación y salvación se realizan en y desde la realidad de las víctimas de nuestro tiempo. Así las cosas, es posible reconocer que el punto de partida y de llegada de esta teología son todos aquellos marginados y excluidos por los sistemas de opresión de nuestro continente. Ellos representan el "lugar teológico" de la revelación de Dios (Ellacuría, 2000a: pp. 148 - 153), lugar de experiencia y contemplación; y así mismo el "lugar teologal” (Ellacuría, 2000a: pp. 235 - 237) de su acontecer, pues es en su praxis de liberación como puede apropiarse el actuar histórico-salvífico del Padre que interpela a los creyentes y a la Iglesia hacia una praxis de igual índole.

El 'lugar teologal' que representan los empobrecidos y excluidos de los pueblos latinoamericanos es la base histórica y social de la teología de la liberación. Esta es su centralidad y marco práxico y epistemológico a partir del cual se desarrolla y repercute en la realidad histórica a fin de transformarla. Los pobres no 
son un instrumento para la teología de la liberación, es la realidad histórica de la cual nace, a la cual se debe y por la cual emprende una praxis que la trascienda, para posibilitar la realización efectiva del reinado de Dios (Mt 4, 26). Al atender al carácter articulador entre 'liberación' y 'salvación', la experiencia mística y de contemplación de Dios en el "pueblo crucificado" (Ellacuría, 2000b: pp. 152 - 153) es aquella que dinamiza la liberación material e histórica de la realidad; y a sí mismo posibilita su salvación, es decir, la transformación de las estructuras de opresión y la constitución de nuevas realidades históricas que permitan la realización integral del ser humano y la prevalencia su dignidad y derechos.

Es importante aclarar que la teología de la liberación no concibe al sujeto como un agente pasivo de su historia en razón de su condición. Gracias a sus anhelos y esperanzas de liberación, aspectos que configuran su praxis histórica, la teología y la praxis de liberación se vinculan con ellas y procuran también la liberación de las estructuras que les oprimen y violentan su humanidad. Este aspecto señala que el carácter sistemático de esta teología se orienta desde la acción misericordiosa con aquellos que han sido marginados y excluidos de la sociedad. En atención a la parábola del Buen Samaritano (Lc 10, 25 - 37), esta teología, y propiamente el creyente y la Iglesia, asumen una actitud samaritana a fin de procurar una liberación integral y una transformación estructural de la historia desde los clamores del pueblo. Esta actitud, en palabras de Sobrino es el "principio-misericordia", eje central que configura a la teología de la liberación y por consiguiente, a la praxis teologal del creyente y de la Iglesia.

Digamos que por «principio-misericordia» entendemos aquí un específico amor que está en el origen de un proceso, pero que además permanece presente y activo a lo largo de él, le otorga una determinada dirección y configura los diversos elementos dentro del proceso. Ese «principiomisericordia» - creemos - es el principio fundamental de la actuación de Dios y de Jesús, y debe serlo de la Iglesia (Sobrino, 1992: p. 32).

Los aspectos señalados al respecto de la teología de la liberación permiten comprender que es un 'lenguaje sobre Dios' cuyo punto de partida y de llegada es la realidad histórica de los pobres y marginados en el contexto latinoamericano. Las necesidades y urgencias de los pueblos, sus esperanzas, luchas y anhelos de liberación son el 'principio-misericordia' que vertebra su sistematicidad y su operatividad en el creyente y en la Iglesia. Como bien enuncia Gutiérrez, el ‘hacer teología' solo es posible si hay una mística y una praxis de fe desde la realidad, es decir, una relación directa con la historia. 
Ahora bien, al reconocer que son los pobres y marginados de nuestro tiempo el lugar 'teológico' y 'teologal' de la presencia de Dios, es a partir de ellos como será posible dinamizar no solo la contemplación de Dios en la realidad histórica, sino también, desde el seguimiento histórico de Jesús, una praxis teologal de liberación y salvación. Ellacuría enuncia al respecto que es desde la materialidad de los pobres y de su pobreza como será posible dinamizar dicha liberación y salvación toda vez que sus luchas y acciones de liberación son el lugar 'teologal' en el cual se hace presente la gracia y la acción salvífica de Dios que transforma la realidad histórica (teopraxia) (Ellacuría, 2000a: p. 556). En este sentido,

Será Dios en los pobres el que salvará la historia, pero en unos pobres reales que realmente operarán sobre ella cuando, manteniendo su condición material de pobreza, recuperarán en ella la bienaventuranza total del don de Dios (Ellacuría, 2000a: pp. 587 - 588).

\section{Caracterización de una pedagogía de la teología en perspectiva crítico-liberadora.}

La aproximación a los referentes constitutivos de la pedagogía crítica y la teología de la liberación permiten inferir la relevancia de un aspecto concordante en estas dos propuestas: la urgencia de una praxis liberadora que posibilite la emancipación de los sujetos y la transformación de la realidad histórica. Esta praxis liberadora se hace efectiva al tener en cuenta el carácter crítico y problematizador que adquiere el acto educativo crítico como lugar para el debate, la resistencia y la emancipación de los sujetos frente a las relaciones hegemónicas de poder y dominación ideológica que la escuela tradicional y la hegemonía cultural imponen. Así mismo, es una praxis liberadora que se hace efectiva al reconocer cómo un auténtico 'lenguaje sobre Dios' es un proceso de razonabilidad de la fe desde la experiencia del creyente y la Iglesia con respecto a la contemplación del acontecer histórico de Dios en el sufrimiento de los pueblos marginados y oprimidos; y de igual forma, desde el despliegue de una praxis teologal que aporta a la transformación de la realidad en solidaridad y resistencia con las luchas de liberación de los pueblos empobrecidos en el contexto latinoamericano.

De esta manera, ante el interés de caracterizar una pedagogía de la teología, ambos referentes señalan que su punto de partida y de llegada es el sujeto, su experiencia vital y el significado que subyace a la praxis liberadora y 
transformadora de su realidad como mediación propicia que articula el acto educativo. La concepción de una pedagogía de la teología desde esta perspectiva supone apropiar como dinamismo fundamental para la construcción y enseñanza del saber teológico la experiencia de fe del creyente desde su realidad histórica y su significación (contemplación y praxis), el sentido de la praxis teologal a la luz de las implicaciones que tiene la revelación histórica de Dios en los signos de los tiempos y el seguimiento de Jesús en su contexto; y así mismo, el esfuerzo por articular una liberación y salvación de la historia en asocio con las acciones liberadoras de los pueblos sometidos a la injusticia y la opresión.

Así las cosas, esta pedagogía asume como aspecto fundante la enseñanza del conocimiento teológico a partir del significado que representa para el creyente su experiencia vital de acuerdo a sus necesidades e intereses (McLaren, 1984: p. 221) en relación directa con los dinamismos e interpelaciones que subyacen a su experiencia de fe. Esta concepción antropológica deja entrever que el interés de esta pedagogía está puesto en comprender el proceso de enseñanza del saber teológico desde la representación biológica, histórica y social de la persona en su contexto (Ellacuría, 1991: p. 390); y así mismo, desde su reconocimiento como un sujeto creyente en las coordenadas propias de su experiencia de fe vinculada al dinamismo de su realidad.

Ahora bien, al tener en cuenta que para la fe del creyente y de la Iglesia, el lugar 'teológico' y 'teologal' del acontecer histórico de Dios son los excluidos de la sociedad, esta propuesta pedagógica asume como dinamismo principal del proceso pedagógico el ejercicio de apropiación de los 'signos de los tiempos' y su significado para el creyente y la Iglesia (Ellacuría, 2002a: p. 369). Este aspecto no solo es mediación que contribuye al acrecentamiento de la fe del sujeto, sino también mediación pedagógica que aporta a la construcción del saber teológico conforme a las características del acto revelador de Dios en la historia. De esta manera, dar razón del proceso de enseñanza del saber teológico en clave crítico-liberadora implica, antes que un ejercicio de teorización del conocimiento, su configuración desde la experiencia de fe de la persona en su realidad. Esta apreciación valida la interacción que se hace entre pedagogía crítica y teología de la liberación con respecto al significado de la praxis liberadora como mediación que transforma la realidad histórica y el acto educativo, pues la construcción del conocimiento teológico tiene su asidero en la constitución de la experiencia de fe del cristiano en su realidad.

La apropiación de la realidad histórica por parte del sujeto es un ejercicio concomitante a su naturaleza. No es posible aprehender el significado de una 
realidad con sus dinámicas y tensiones sino a partir de la capacidad sentiente e intelectiva de la persona (Zubiri, 1981). De ahí que el dinamismo de la experiencia de fe del creyente solo es posible toda vez que el reconocimiento del acontecer histórico de Dios depende de su apropiación desde el sufrimiento de los pueblos empobrecidos y marginados en su realidad. Estos aspectos permiten comprender que el despliegue del acto educativo está mediado por la significación de la realidad, la cual desde la perspectiva de fe cristiana, da razón del 'lugar' teológico y teologal del acontecer de Dios en los sufrimientos, luchas y esperanzas de liberación de los pueblos empobrecidos y marginados de la sociedad. Es importante reiterar la principalidad de la capacidad intelectiva y sentiente del sujeto, ya que sin ella no sería posible hacer apropiación crítica de la realidad. Al respecto, $\mathrm{Zu}$ biri describe esta capacidad de la siguiente manera:

Sentir algo real es formalmente estar sintiendo intelectivamente. La intelección no es intelección 'de' lo sensible, sino que es intelección 'en' el sentir mismo. Entonces, claro está, el sentir es inteligir: es sentir intelectivo. Inteligir no es, pues, sino otro modo de sentir (diferente del puro sentir). Este 'otro modo' concierne a la formalidad de lo sentido. La unidad de inteligencia y de sentir es la unidad misma de contenido y formalidad de realidad. Intelección sentiente es aprehensión impresiva de un contenido en formalidad de realidad: es justo la impresión de realidad. El acto formal de la intelección sentiente es, repito, aprehensión impresiva de la realidad (Zubiri, 1981: p. 84).

Una pedagogía de la teología da razón de la enseñanza del saber teológico desde el proceso de intelección sentiente del creyente en su realidad. Si desde el acto educativo crítico el aspecto fundamental es la experiencia vital del sujeto, a partir del proceso de aprehensión impresiva de la realidad es necesario señalar que el acto educativo está mediado por el sentir intelectivo del sujeto en su realidad. En la lógica de la pedagogía de la teología, es un acto educativo que asocia la aprehensión de la realidad del sujeto (experiencia vital) desde la perspectiva de la fe cristiana, hecho que posibilita la enseñanza de un 'lenguaje sobre Dios' desde la comprensión de la revelación histórica de Dios en la realidad, su razonabilidad y la praxis que demanda.

La praxis liberadora que constituye a la pedagogía de la teología está mediada por el giro que exige comprender la construcción de conocimiento teológico desde la experiencia vital del creyente. Este aspecto transforma la dinámica del acto educativo, con esto permite concebirlo como un proceso que surge de la 
aprehensión impresiva de la realidad por parte del cristiano. Ahora bien, es necesario señalar cómo esta perspectiva implica establecer un proceso de construcción y enseñanza del saber teológico en tres pasos fundamentales. En atención a la propuesta de Ignacio Ellacuría, este proceso se caracteriza por ser una dinámica que implica 'hacerse cargo de la realidad', 'cargar con la realidad' y 'encargarse de la realidad' como mediación que dinamiza esta propuesta pedagógica

La capacidad de intelección sentiente del sujeto como dinamismo que configura el aprehensión impresiva de realidad orienta el desarrollo de esta pedagogía señalando que es necesario hacerse cargo de la realidad con sus particularidades históricas, políticas y sociales. Al atender a las características de la fe cristiana, es una pedagogía que se orienta a partir de la aprehensión de los "signos de los tiempos" de la historia (GS, 11) como lugar de la revelación de Dios:

[...] el hacerse cargo de la realidad, supone un estar en la realidad de las cosas - y no meramente un estar ante la idea de las cosas o en el sentido de ellas -, un estar "real" en la realidad de las cosas que, en su carácter activo de estar siendo, es todo lo contrario de un estar cósico e inerte e implica un estar entre ellas, a través de sus mediaciones materiales y activas [...]. (Ellacuría, 2000a: p. 208).

El 'principio-misericordia' que señala Sobrino al respecto del actuar de la Iglesia y de los creyentes adquiere validez desde esta perspectiva (Sobrino, 1992: pp. 37 - 39). La experiencia de fe configurada desde la realidad histórica es un asunto que exige realizar una opción vital frente al proceso de emancipación, liberación y transformación social que emprenden los pobres de nuestro tiempo. La relación directa del cristiano con los pobres es fruto de su reconocimiento y contemplación como el 'Cristo crucificado' de hoy (Ellacuría, 2000b: p. 152), aspecto trascendental que determina el significado y dinamismo de su fe y su praxis.

Una pedagogía de la teología que se 'hace cargo de su realidad' da cuenta de su carácter crítico y liberador. La experiencia vital del creyente fruto de su aprehensión impresiva de realidad (intelección sentiente) es un aspecto que se problematiza críticamente a fin de comprender qué es aquello que la constituye y a qué lo lleva desde la contemplación del pueblo oprimido como presencia histórica y salvífica de Dios. En esta instancia, la relación 'profesor - estudiante' adquiere relevancia toda vez que se pretende articular la experiencia de fe en razón del significado que subyace a la persona como resultado de su interacción con su realidad. 
La construcción del saber teológico asume como 'acto primero' la realidad histórica y su reconocimiento como 'lugar' teológico y teologal de la revelación de Dios. Su 'acto segundo' es dar razón de este acontecer de Dios. Para ello, necesita la experiencia de fe del creyente, pero al mismo tiempo, su sentido desde el seguimiento histórico de Jesús. Es decir, el acto educativo implica articular la experiencia de fe del sujeto en relación directa con su realidad y el significado que tiene a partir del seguimiento de Jesús, representado principalmente en la Sagrada Escritura, y seguidamente en el Magisterio Eclesiástico y la tradición teológica.

El seguimiento histórico de Jesús que resalta la teología de la liberación (Ellacuría, 2000b: p. 21), y en general toda la teología, implica asumir como propia la historia y hacer opción en ella de igual forma que él lo hizo. Al interior del sistema político-religioso en el que vivió Jesús, él hizo opción por los marginados de su tiempo: enfermos, pecadores, etc. De igual manera, el seguimiento de Jesús implica esta opción en nuestro tiempo, esto es, optar por aquellos que son marginados y excluidos de la sociedad por su condición o porque la hegemonía económica y social así lo ha determinado en razón de sus intereses. De ahí que el siguiente momento del acto educativo se entienda como un "cargar con la realidad", es decir, como un proceso que implica apropiación histórica y real de la historia y las exigencias que trae por sí misma:

[...] el cargar con la realidad, señala el fundamental carácter ético de la inteligencia, que no se le ha dado al hombre para evadirse de sus compromisos reales, sino para cargar sobre sí con lo que son realmente las cosas y con lo que realmente exigen [...]. (Ellacuría, 2000a: p. 208)

La pedagogía de la teología asume un dinamismo histórico a través del cual la enseñanza del saber teológico no puede desvincularse de la realidad. Más aún, no puede instrumentalizarla, pues antes que nada, es su razón fundamental al tener en cuenta el carácter histórico que adquiere la revelación de Dios en la persona de Jesús y en los signos de la historia. Así las cosas, el carácter ético que orienta esta propuesta pedagógica implica desarrollar un ejercicio de razonabilidad de la fe que vincule experiencia y tradición a fin de hacer apropiación crítica de la realidad y con ello, de las características del conocimiento teológico desde la perspectiva del seguimiento de Jesús.

La pedagogía crítica señala la urgencia de una praxis pedagógica de liberación como mediación para la ruptura de la cultura hegemónica dominante, en donde sea "posible transformar críticamente la experiencia social por medio de un lenguaje y de una praxis que pongan al educador y al estudiante en 
condiciones de situarse a sí mismo como activo agente social, cultural e histórico" (McLaren, 1994: p. 31). Desde esta perspectiva, la construcción y enseñanza del saber teológico supone por parte del profesor y del estudiante asumir roles similares, pues su vinculación directa con la realidad a través de su experiencia de fe no solo les lleva a comprenderla en su devenir o a asumir un carácter ético frente a ella, sino también a ejercer un papel protagónico por el cual sea posible deslegitimar las estructuras de opresión y marginación que imperan hegemónicamente en la sociedad desde su praxis de fe. En este sentido,

[...] encargarse de la realidad, señala el carácter práxico de la inteligencia, que sólo cumple con lo que es, incluso en su carácter de conocedora de la realidad y compresora de su sentido, cuando toma a su cargo un hacer real [...]. (Ellacuría, 2000a: p. 208)

Profesor y estudiante deben dar razón de su papel como agentes orgánicos de la realidad. Ambos, como "intelectuales transformativos" (Giroux, 1990: p. 150 - 151), tienen la posibilidad para dinamizar una praxis transformadora en ella. El carácter práxico de la inteligencia que señala Ellacuría permite comprender cómo el acto intelectivo y sentiente del sujeto no es un puro sentir como expresa Zubiri, sino un inteligir que implica una apropiación de la realidad en su sentido profundo así como de las interpelaciones que en ella subyacen conforme a las dinámicas sociales, económicas, políticas y culturales a las cuales es sometida por las hegemonías dominantes.

Con esto, si la pedagogía de la teología propicia la construcción y enseñanza del saber teológico desde las características enunciadas, es posible señalar que se constituye en sí misma como una praxis con un 'hacer real' específico. Es un 'hacer real' que transforma el significado del proceso pedagógico en sí mismo. Es un 'hacer real' liberador y trascendente que propicia la construcción y enseñanza del saber teológico desde la experiencia vital del creyente en su realidad y las implicaciones que trae en razón del seguimiento histórico de Jesús. Y, en último término, es un 'hacer real' que dinamiza su praxis de fe (teologal) desde la articulación del conocimiento teológico en razón de la experiencia de fe y la tradición eclesial que lo enmarca.

La caracterización de una pedagogía de la teología desde esta perspectiva crítico-liberadora señala la urgencia de la experiencia de fe como base para la construcción del saber teológico. Esta pedagogía no desconoce la tradición teológica de la Iglesia. Como bien ha sido enunciado, es una reflexión que aporta a su enseñabilidad y tiene como referente el dinamismo experiencial y subjetivo 
de la pedagogía crítica y el carácter transformador de la teología de la liberación (Gutiérrez, 1990: p. 72). La pedagogía de la teología depende de estos dos factores, ahora bien, su relevancia será dinamizar la experiencia del creyente desde su capacidad para aprehender impresivamente su realidad, de tal manera que le permita articular una praxis histórico-trascendente y salvífico-liberadora en razón del seguimiento histórico de Jesús y del sentido transformador de su acción con los marginados y excluidos de su tiempo.

El profesor y el estudiante, al ser 'intelectuales transformativos' son agentes de su realidad. Su capacidad para inteligir sentientemente la realidad les brinda la capacidad para construir un 'lenguaje sobre Dios' a través de su interacción y significación en base de su experiencia de fe y de seguimiento de Jesús. En razón de la dinámica del proceso pedagógico (hacerse cargo, cargar y encargarse de la realidad), es preciso señalar que la construcción de conocimiento teológico depende de la capacidad del sujeto para inteligir sentientemente aquellos "signos de los tiempos" (GS 4. 11) en los cuales la presencia de Dios es operante. De esta manera, el acto educativo estará orientado hacia el desarrollo de la inteligibilidad del conocimiento teológico en razón de la experiencia vital del sujeto desde su vida de fe (aprehensión impresiva de realidad), articulado con la tradición teológica que favorece su apropiación y hermenéutica, y con el direccionamiento de una praxis teologal que posibilite la transformación de su realidad.

\section{Conclusiones}

El ejercicio de interacción dialógica entre pedagogía crítica y teología de la liberación permite caracterizar una pedagogía de la teología para tener en cuenta la significación de la experiencia de fe del creyente en relación directa con su realidad histórica. Esta pedagogía no tiene por opción transmitir el conocimiento de manera sistemática, antes bien, busca construirlo desde la experiencia de fe del creyente y el significado de la tradición teológica en la Iglesia, de tal manera que sea un saber actualizado que dinamice la praxis teologal del sujeto en relación recíproca a las acciones transformadoras de los pobres en el contexto latinoamericano.

Es una pedagogía que no apela a la racionalidad tecnocrática ni instrumental del sujeto y del conocimiento. Señala la pertinencia del profesor y del estudiante como 'intelectuales transformativos', esto es, agentes de la realidad capaces de inteligir sentientemente y comprender aquello que particulariza la dinámica de la sociedad; y en razón de ello, constituirse como actores que despliegan una praxis 
transformadora que aporte a su liberación de las estructuras de opresión. De ahí la necesidad de problematizar la experiencia de fe y asumirla desde una postura crítica (McLaren, 1990: p. 18), pues en el reconocimiento de su significación teológica y teologal será posible establecer el ejercicio de interacción dialógica con la tradición eclesial, y a partir de ello, no solo dar razón de un proceso de construcción y enseñanza del conocimiento teológico, sino también de las implicaciones que trae para la vida de fe del creyente y de la Iglesia.

En síntesis, esta pedagogía de la teología en perspectiva crítico-liberadora tiene como punto de partida al creyente con sus anhelos, deseos e intereses. Su finalidad es la articulación de un proceso pedagógico desde la experiencia de fe en la realidad (hacerse cargo de la realidad), la apropiación de sus implicaciones éticas (cargar con la realidad), y en ello, el despliegue de una praxis teologal que aporte a su transformación (encargarse de la realidad). De ahí que:

En la enseñanza de la teología no se trata, simplemente, de informar respecto de determinados contenidos, sino que de remitir al acontecimiento de la autocomunicación de Dios en Cristo. ¿Cómo estamos detrás de aquello que enseñamos? ¿Cómo está nuestra vida personal, social, comunitaria, eclesial? ¿ $\mathrm{O}$, simplemente, como hijos de nuestro tiempo, vivimos una suerte de esquizofrenia entre fe y vida? (Silva, 2010: p. 243)

\section{Referencias}

Berríos, F. (2012). Pedagogía en teología: el aporte de Karl Rahner. Revista Veritas, 26, 187 - 196. Doi: http://dx.doi.org/10.4067/S0718-92732012000100009

CELAM (1979). Documento de Puebla. III Conferencia General del Episcopado Latinoamericano. Bogotá: CELAM.

Concilio Vaticano II (1965). Constitución Dogmática Dei Verbum [DV] sobre la divina revelación. Vaticano: Vaticano.

(1965). Constitución Dogmática Gaudium et Spes [GS] sobre la Iglesia en el mundo actual. Vaticano: Vaticano.

Ellacuría, I. (2002a). Fe y justicia. En Ellacuría, I. (Ed.), Escritos teológicos III, pp. 307 373. San Salvador: UCA Editores.

Ellacuría, I. (2000b). ¿Por qué muere Jesús y por qué lo matan? En Ellacuría, I. (Ed.), Escritos teológicos II, pp. 67 - 88. San Salvador: UCA Editores. 
. (2000b). Utopía y profetismo desde América Latina. Un ensayo concreto de soteriología histórica. En Ellacuría, I. (Ed.), Escritos teológicos II, pp. 233 - 292. San Salvador: UCA Editores.

(2000b). El pueblo crucificado. Ensayo de soteriología histórica. En Ellacuría, I. (Ed.), Escritos teológicos II, pp. 137 - 170. San Salvador: UCA Editores.

. (2000b). Aporte de la teología de la liberación a las religiones abrahámicas en la superación del individualismo y el positivismo. En Ellacuría, I. (Ed.), Escritos teológicos II, pp. 193 - 232. San Salvador: UCA Editores.

. (2000a). Los pobres, "lugar teológico" en América Latina. En Ellacuría, I. (Ed.), Escritos teológicos I, pp. 139 - 161. San Salvador: UCA Editores.

. (2000a). Hacia una fundamentación del método teológico latinoamericano. En Ellacuría, I. (Ed.), Escritos teológicos I, pp. 187 - 218. San Salvador: UCA Editores.

. (2000a). Relación entre teoría y praxis en la teología de la liberación. En Ellacuría, I. (Ed.), Escritos teológicos I, pp. 235 -245. San Salvador: UCA Editores.

. (2000a). Historicidad de la salvación cristiana. En Ellacuría I. (Ed.), Escritos teológicos I, pp. 535 - 596. San Salvador: UCA Editores.

. (2000a). En torno al concepto y a la idea de liberación. En Ellacuría, I. (Ed.), Escritos teológicos I, pp. 629 - 657. San Salvador: UCA Editores.

. (1991). Filosofía de la realidad histórica. Madrid, España: Ed. Trotta.

Freire, P. (1988). Algunas notas sobre concientización. En Freire, P. (Ed.), La importancia de leer y el proceso de liberación, pp.82 - 93. México: Siglo XXI.

Giroux, H. (2013). La pedagogía en tiempos oscuros. Praxis educativa 17 (1-2), pp. 13 - 26.

. (2001). Los profesores como intelectuales transformativos. Revista Docencia 15 , pp. $60-66$.

. (1997). La pedagogía radical como política cultural: Más allá del discurso de la crítica y el antiutopismo. En McLaren, P. (Ed.), Pedagogía crítica y cultura depredadora, pp. 47 - 77. Barcelona: Paidós.

(1990). Los profesores como intelectuales transformativos. En Giroux, H. (Ed.), Los profesores como intelectuales. Hacia una pedagogía crítica del aprendizaje, pp. 171 - 178. Barcelona: Paidós.

. (1990). Pedagogía crítica, política cultural y discurso de la experiencia. En Giroux, H. (Ed.), Los profesores como intelectuales. Hacia una pedagogía crítica del aprendizaje, pp. 135 - 157. Barcelona: Paidós.

Gutiérrez, G. (1995). Hablar de Dios desde el sufrimiento del inocente. Una reflexión sobre el libro de Job. Salamanca: Sígueme.

. (1990). Teología de la liberación. Perspectivas. Salamanca: Sígueme.

Juan Pablo II. (1992) Catecismo de la Iglesia Católica. Vaticano: Vaticano. En: http:// www.vatican.va/archive/catechism_sp/index_sp.html 
(1979) Exhortación apostólica Catechesi Tradendae. Vaticano: Vaticano. En: http://goo.gl/BDdNyN

McLaren, P. (1997). Multiculturalismo y crítica posmoderna. Hacia una pedagogía de resistencia y transformación. En McLaren, P. (Ed.), Pedagogía crítica y cultura depredadora, pp. 236 - 266. Barcelona: Paidós.

. (1994). Pedagogía crítica: Construcción de un arco de sueño social y de una entrada a la esperanza. En McLaren, P. (Ed.), Pedagogía crítica, resistencia cultural y la producción del deseo, pp. 17 - 48. Buenos Aires: Ideas.

. (1990). Prefacio: Teoría crítica y significado de la esperanza. En Giroux, H.

(Ed). Los profesores como intelectuales. Hacia una pedagogía crítica del aprendizaje, pp. 13 - 24. Barcelona: Paidós.

. (1984). Pedagogía crítica: una revisión de los principales conceptos. En McLaren, P. (Ed.), La vida en las escuelas. Una introducción a la pedagogía crítica en los fundamentos de la educación, pp. 193 - 234. México D. F.: Siglo XXI Editores.

Oliveros, R. (1990). Historia de la teología de la liberación. En Ellacuría, I. \& Sobrino, J. (Ed.), Mysterium Liberationis. Conceptos fundamentales de la teología de la liberación I, pp. 17 - 50. Madrid: Editorial Trotta.

Silva, J. (2010). Pedagogía de la enseñanza teológica. La condescendencia de Dios como clave hermenéutica fundamental para la enseñanza teológica. Teología y vida, 51, pp. 233 - 255. Doi: http://dx.doi.org/10.4067/S0049-34492010000100009

Sobrino, J. (1992). El principio-misericordia. Bajar de la cruz a los pueblos crucificados. Santander: Sal Terrae.

Wicks, J. (2011). Introducción al Método Teológico. Estella (Navarra): Verbo Divino. Zubiri, X. (1981). Inteligencia sentiente. Madrid: Alianza Editorial. 